\title{
New coronary transfer technique for transposition of the great arteries with a single coronary artery
}

\author{
Yoshihiro Ko, MD, Koji Nomura, MD, and Mitsutaka Nakao, MD, Saitama, Japan
}

From the Department of Cardiovascular Surgery, Saitama Children's Medical Center, Saitama, Japan.

Disclosures: Authors have nothing to disclose with regard to commercial support.

Received for publication Sept 23, 2016; revisions received Oct 14, 2016; accepted for publication Oct 20, 2016; available ahead of print Dec 18, 2016

Address for reprints: Yoshihiro Ko, MD, Department of Cardiovascular Surgery, Saitama Children's Medical Center, 2100 Magome, Iwatsuki-city, Saitama 339-0077, Japan (E-mail: koyoshihiro@yahoo.co.jp).

J Thorac Cardiovasc Surg 2017;153:1150-2

$0022-5223 / \$ 36.00$

Copyright (c) 2016 by The American Association for Thoracic Surgery

http://dx.doi.org/10.1016/j.jtcvs.2016.10.068

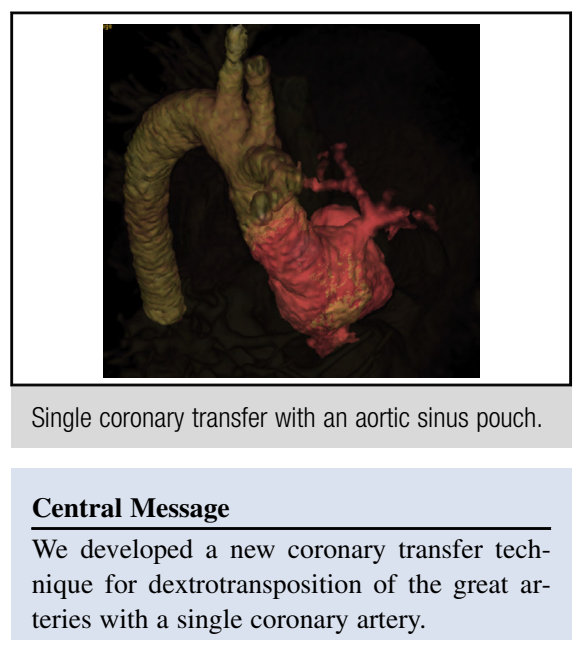

The arterial switch operation for transposition of the great See Editorial Commentary page 1153. arteries (TGA) has been well described, and variations have been developed for all common variants of coronary artery anatomy. Although numerous coronary transfer techniques for TGA with coronary artery anomalies have been reported, anomalies such as a single coronary artery or coronary arteries originating from a single aortic sinus are still associated with increased risk. We developed a new coronary transfer technique for dextro-TGA with a single coronary artery.

\section{CLINICAL SUMMARY}

A boy was born at term with moderate cyanosis. Chest radiography indicated cardiomegaly along with normal pulmonary vascular markings in the lung. An electrocardiogram revealed sinus rhythm with no ST change. Echocardiography indicated bidirectional shunting through an atrial septal defect and left-to-right shunting through a large patent ductus arteriosus. The coronary main trunk was single and short, arising from the left-facing sinus (Figure 1). The pulmonary valve was tricuspid with no regurgitation. On postnatal day 2 , the patient underwent balloon atrial septostomy. Angiography enabled identification of the coronary artery pattern as Shaher 3a, and left ventricular morphology and function were reasonable. On postnatal day 15 , at a weight of $3.5 \mathrm{~kg}$, the patient underwent an arterial switch operation.

Under cardiopulmonary bypass, the ascending aorta was transected $15 \mathrm{~mm}$ above the right ventricle. A single coronary orifice was present in the front of the left-facing sinus. Because the coronary trunk was very short and distant from

the posterior pulmonary artery, we made an aortic sinus pouch to improve the extension and flexibility of the coronary trunk. We cut the left- and right-facing sinuses away from the aorta and sutured the edge of the aortic sinus button to make a long tubular pouch on the proximal end of the coronary trunk. The pulmonary artery was then transected just below the bifurcation. A triangular tip of the pulmonary trunk was resected, and the pouch was cut $6 \mathrm{~mm}$ vertically and anastomosed to the pulmonary trunk in a double-barrel manner (Figure 2 and Video 1). The ascending aorta was reconstructed with the LeCompte maneuver, and the pulmonary artery was reconstructed with fresh pericardium. The atrial septal defect was closed directly. The patient had an uneventful postoperative course, and postoperative computed tomography indicated a smooth coronary route with no obstructions in the aorta or pulmonary artery (Figure 1).

\section{DISCUSSION}

The arterial switch operation has become a standard surgical procedure for TGA, and its current mortality risk is very low, even in cases with complex coronary arteries. ${ }^{1}$ Yet some authors remain concerned about the safety of direct coronary reimplantation in some cases, such as in out case. A single coronary artery with TGA often has limited mobility because of s short coronary trunk and the coronary loop around the great arteries. Sakamoto and colleagues ${ }^{2}$ determined that a high risk was associated with direct reimplantation in cases where the angle between a 

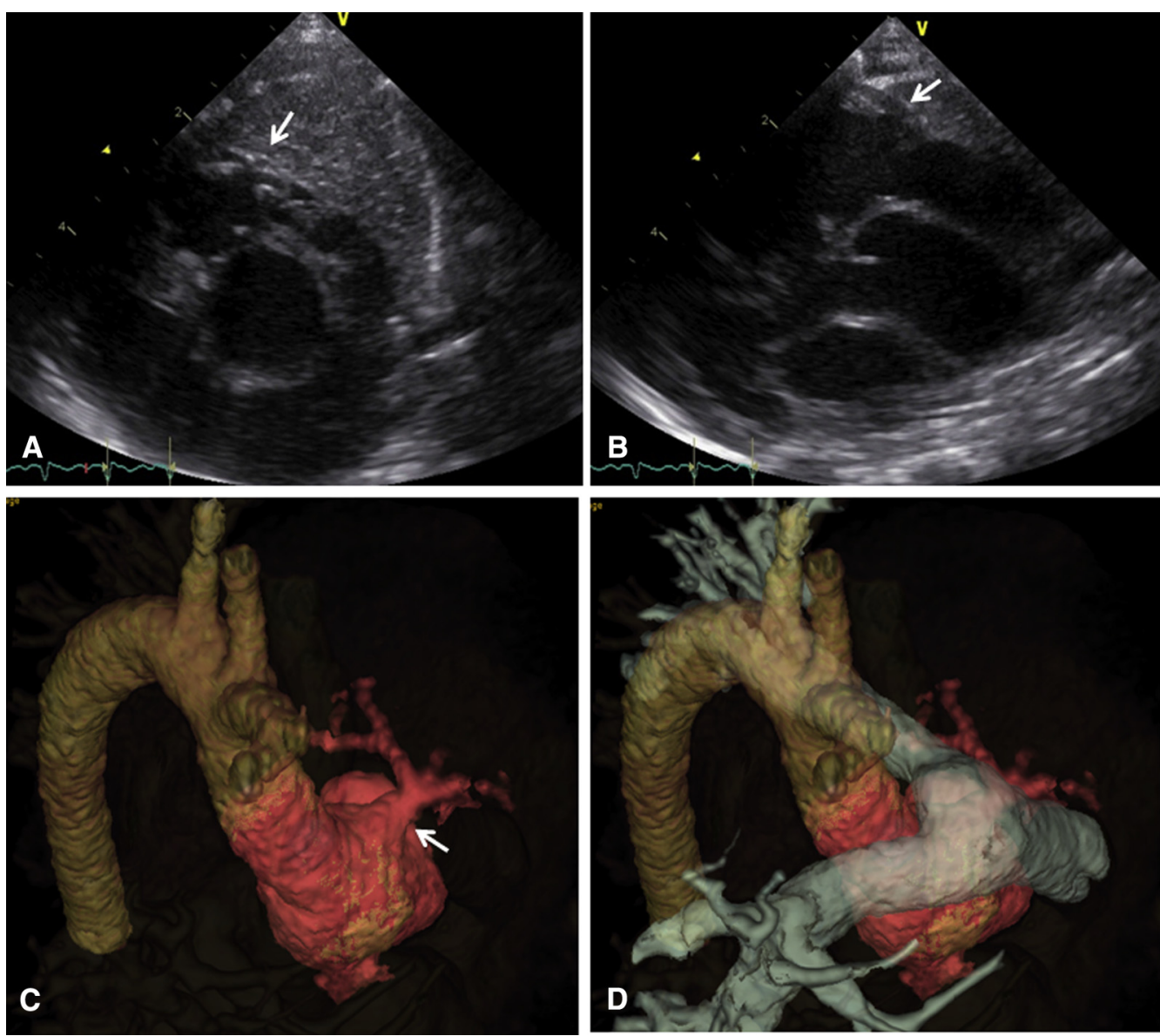

FIGURE 1. A and B, Preoperative echocardiography. A, The single coronary artery arises from the left-facing sinus in short-axis view. B, The single coronary artery trunk is distant from the posterior pulmonary artery in long-axis view. C and D, Postoperative computed tomography. C, The aortic sinus pouch and coronary branches. D, No obstruction in the neopulmonary artery.
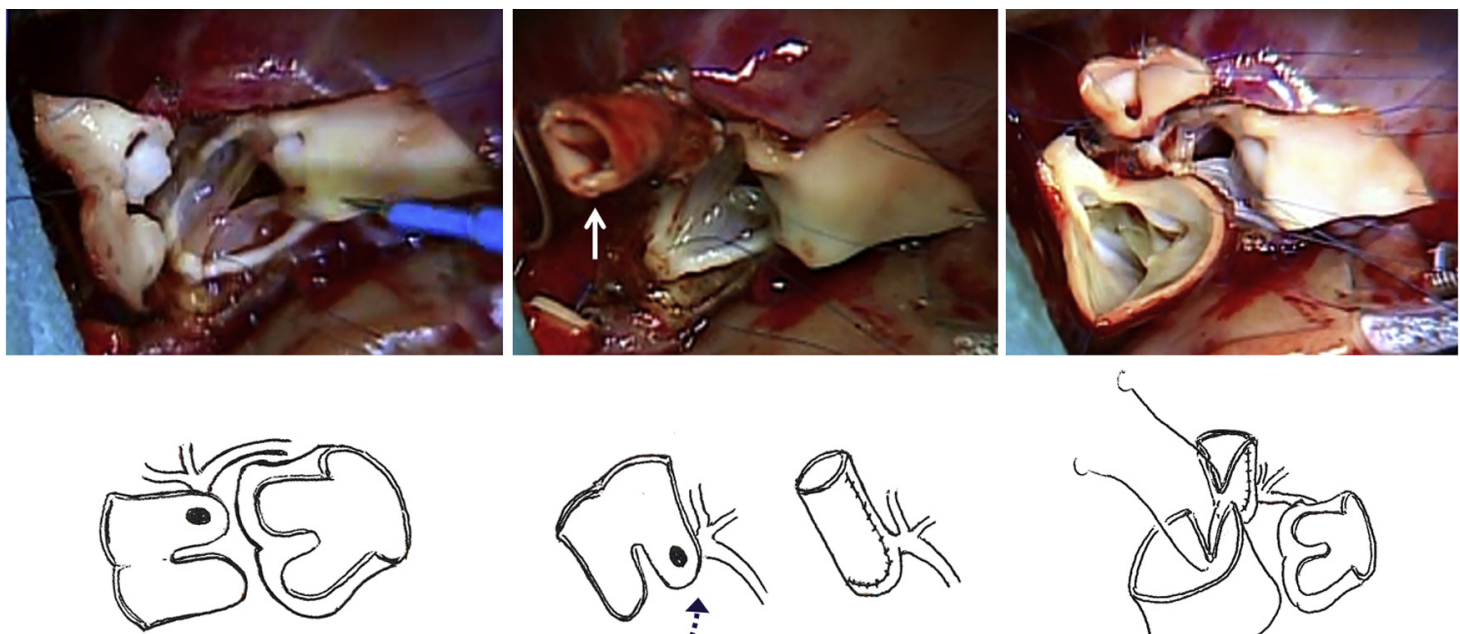

A
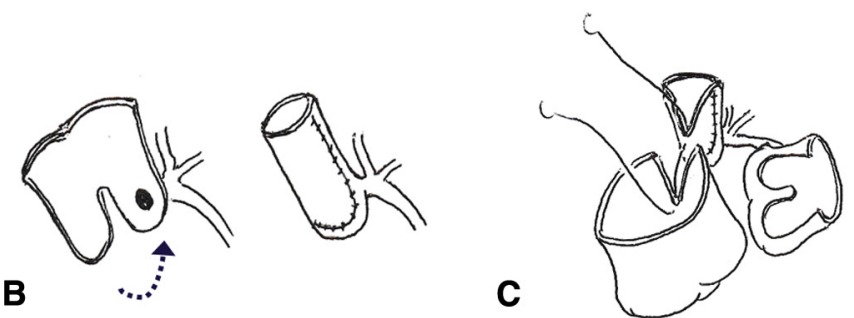

FIGURE 2. Operative photographs (top) and drawings (bottom). A, The coronary orifice in the left-facing sinus; removal of the left- and right-facing aortic sinuses from the aortic trunk. B, The aortic sinus pouch (long tubular pouch on the proximal end of the main coronary trunk). C, Double-barreled anastomosis of aortic sinus pouch and pulmonary trunk. 


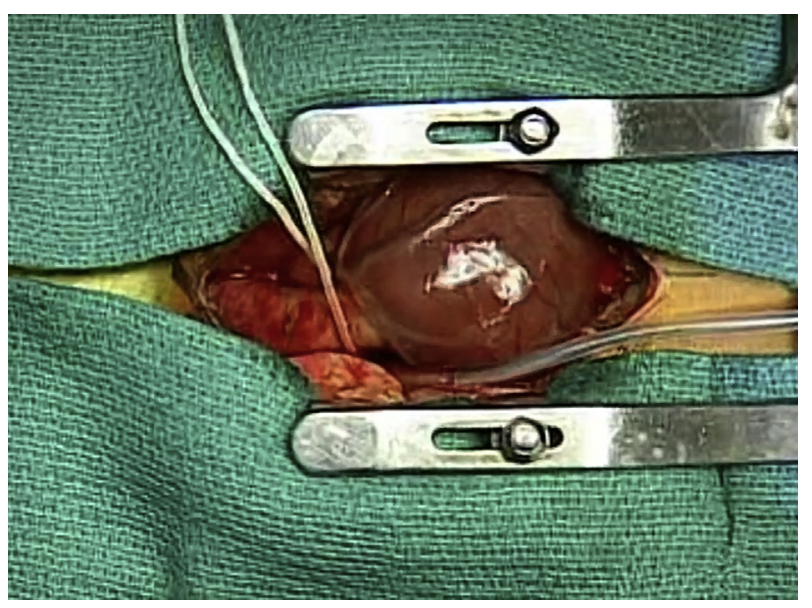

VIDEO 1. Single coronary artery transfer technique with an aortic sinus pouch. Video available at: http://www.jtcvsonline.org/article/ S0022-5223(16)31468-4/addons.

line drawn from the center of the aorta to the pulmonary artery and one drawn from the aorta to the coronary orifice was greater than $75^{\circ}$. In our case, this angle was $100^{\circ}$. In such cases, there are several options. For coronary trunk extension, Parry and associates ${ }^{3}$ attempted an additional autopericardial patch. For in situ coronary reallocation, Yacoub and colleagues ${ }^{4}$ anastomosed the superior edge of the coronary button to the posterior pulmonary trunk, whereas Murthy and coworkers ${ }^{5}$ sutured the pulmonary artery flap around the inner coronary orifice.

Our procedure allows us to regulate the length of the aortic sinus pouch and the direction of its anastomosis to the pulmonary trunk. The pouch is easy to make with a large button of the aortic wall and a simple suture line, and it is completely separate from the pulmonary route. This procedure thus may reduce the risk of coronary thrombosis, shrinkage, distortion, compression, and pulmonary stenosis. In addition, the pouch can be made regardless of the site of coronary orifice, so that our procedure may be used in cases with coronaries arising from a single sinus or intramural coronary arteries. In most single coronary cases, direct reimplantation is possible and recommended, but our technique may become a useful option for borderline cases or for complex cases in which future extension of the coronary route by pulmonary stenosis is a concern.

In conclusion, this technique is simpler and safer than previously reported procedures. To our knowledge, this is the first report of a coronary transfer technique that uses an aortic sinus pouch for dextro-TGA with a single coronary artery.

\section{References}

1. Qamar ZA, Goldberg CS, Devaney EJ, Bove EL, Ohye RG. Current risk factors and outcomes for the arterial switch operation. Ann Thorac Surg. 2007;84: 871-8; discussion 878-9.

2. Sakamoto K, Yokota M, Kyoku J, Kitano M, Mizuhara T, Nishii H. [Arterial switch operation for transposition of the great arteries with single coronary artery "Shaher type 3"]. Jpn J Cardiovasc Surg. 1990;19:1334-7. Japanese.

3. Parry AJ, Thurm M, Hanley FL. The use of 'pericardial hoods' for maintaining exact coronary artery geometry in the arterial switch operation with complex coronary anatomy. Eur J Cardiothorac Surg. 1999;15:159-64; discussion 164-5.

4. Yacoub MH, Radley-Smith R. Anatomy of the coronary arteries in transposition of the great arteries and methods of their transfer in anatomical correction. Thorax. 1978;33:418-24.

5. Murthy KS, Coelho R, Kulkarni S, Ninan B, Cherian KM. Arterial switch operation with in situ coronary reallocation for transposition of great arteries with single coronary artery. Eur J Cardiothorac Surg. 2004;25:246-9. 